\title{
Therapeutic Efficacy of Exclusive Enteral Nutrition with Specific Polymeric Diet in Pediatric Crohn's Disease
}

\author{
Yunkoo Kang, Sowon Park, Seung Kim, Sang Yong Kim*, and Hong Koh \\ Department of Pediatrics, Severance Children's Hospital, Yonsei University College of Medicine, Seoul, *Department \\ of Pediatrics, Incheon St. Mary's Hospital, College of Medicine, The Catholic University of Korea, Incheon, Korea
}

\begin{abstract}
Purpose: The efficacy of exclusive enteral nutrition (EEN) with a polymeric diet has not been confirmed in Korean pediatric patients with Crohn's disease (CD). This study aimed to compare the effectiveness of EEN with a specific polymeric diet $\left(\right.$ Encover $\left.^{\mathbb{B}}\right)$ and corticosteroids (CSs) for the induction of remission in Korean pediatric CD patients. Methods: We retrospectively compared data from 51 pediatric $C D$ patients who underwent induction therapy with EEN ( $n=19)$ or CSs $(n=32)$ at Severance Children's Hospital or Incheon St. Mary's Hospital in Korea. The primary endpoint of this study was the rate of clinical remission, defined as a Pediatric Crohn's Disease Activity Index (PCDAI) score $<10$, after 8 weeks of induction treatment. Clinical, laboratory, and growth data at post-induction as well as their changes from baseline were also compared between groups.

Results: After 8 weeks of induction therapy, clinical remission rates were $78.9 \%(15 / 19)$ and $65.6 \%(21 / 32)$ in the EEN and CS groups, respectively ( $p=0.313$ ). No significant differences in PCDAI scores, laboratory variables, and growth parameters were noted between the two groups at post-induction. However, significant changes in albumin levels at post-induction were observed in the EEN group compared to the CS group $(p=0.038)$.

Conclusion: Our results suggest that the effectiveness of EEN with a polymeric diet and CSs for induction therapy did not differ in Korean pediatric CD patients. EEN with a polymeric diet is a good first-line treatment option for the induction of remission in these patients.
\end{abstract}

Key Words: Enteral nutrition, Child, Crohn disease

\section{INTRODUCTION}

Crohn's disease $(C D)$ is a lifelong chronic inflammatory disease of the gastrointestinal tract. Compared with adult-onset $\mathrm{CD}$, pediatric $\mathrm{CD}$ is par- ticularly characterized by rapid progression and extensive intestinal involvement at diagnosis [1]. Additionally, as children are in the growth phase, it is important to provide sufficient nutrients and minimize adverse effects associated with various drugs

Received : April 11, 2018, Revised : June 29, 2018, Accepted : July 3, 2018

Corresponding author: Sang Yong Kim, Department of Pediatrics, Incheon St. Mary's Hospital, College of Medicine, The Catholic University of Korea, 56 Dongsu-ro, Bupyeong-gu, Incheon 21431, Korea. Tel: +82-2-2228-2053, Fax: +82-32-510-5556, E-mail: sykim2010@catholic.ac.kr

Copyright (c) 2019 by The Korean Society of Pediatric Gastroenterology, Hepatology and Nutrition

This is an open-access article distributed under the terms of the Creative Commons Attribution Non-Commercial License (http://creativecommons.org/licenses/by-nc/4.0/) which permits unrestricted non-commercial use, distribution, and reproduction in any medium, provided the original work is properly cited. 
for pediatric CD [2]. Corticosteroids (CSs) have long been used as a treatment for pediatric $\mathrm{CD}$. However, to minimize adverse effects, exclusive enteral nutrition (EEN) is recommended as first-line treatment for the induction of remission in children with CD [3]. EEN has recently become the preferred choice for induction therapy in pediatric $\mathrm{CD}$ in Europe but is less preferred in North America [4,5]. Previous studies have reported that the efficacy rate of EEN for the induction of remission is approximately $70 \%$ to $80 \%[6-8]$.

Two types of EEN for induction therapy are available: monomeric and polymeric diets. A monomeric diet is more expensive and has fewer flavors than a polymeric diet, but no difference in efficacy has been identified between these two diets [9]. Thus, under general circumstances, a polymeric diet is recommended for induction therapy. In a retrospective study, Soo et al. [10] showed the effectiveness of EEN (polymeric or semi-elemental) versus CSs for the induction of remission in pediatric CD patients. Although a polymeric diet tastes better and is less expensive than a monomeric diet, no study has reported the effectiveness of a polymeric diet in Korean pediatric CD patients $[11,12]$. Moreover, the Korean government provides only a monomeric diet for induction therapy in pediatric $C D$ patients.

The present study aimed to compare the effectiveness of two therapeutic regimens (EEN with a commercially available polymeric diet [Encover ${ }^{\mathbb{R}} ; \mathrm{JW}$ Pharmaceutical, Seoul, Korea] and CSs) for induction therapy by analyzing both clinical and laboratory variables in pediatric $C D$ patients.

\section{MATERIALS AND METHODS}

\section{Study subjects and data collection}

This study was a retrospective study conducted at Severance Hospital in Seoul, Korea, and Incheon St. Mary's Hospital in Incheon, Korea, between 2005 and 2017. Medical charts of newly diagnosed pediatric CD patients who had received induction treatment with either EEN or CSs were reviewed. Patients who lacked medical records or who had not adhered to either therapy during the induction period were excluded. Patient data, including baseline demographics, disease classification, Pediatric Crohn's Disease Activity Index (PCDAI) score, height, weight, body mass index (BMI), hematocrit (Hct) level, erythrocyte sedimentation rate (ESR), C-reactive protein (CRP) level, and albumin level, were collected before and after induction therapy. Disease location and behavior had been categorized according to the Montreal classification [13].

\section{Study design}

Comparison was performed between those who had received either EEN (EEN group) or CS during induction (CS group). For the EEN group, a polymeric formula had been orally administered to induce remission. The formula volume had been based on the estimated energy requirements for an ideal weight, with consideration of height. For the CS group, prednisone ( $1 \mathrm{mg} / \mathrm{kg} /$ day) had been initiated either intravenously or orally for 4 weeks and had been weaned over the subsequent 2 to 4 weeks (Fig. 1). The primary endpoint was the rate of clinical remission after 8 weeks of induction therapy with EEN or CSs. Clinical remission was defined as a PCDAI score $<10[14,15]$. The secondary endpoints were changes in the following clinical and laboratory variables: PCDAI score, height Z-score, weight Z-score,

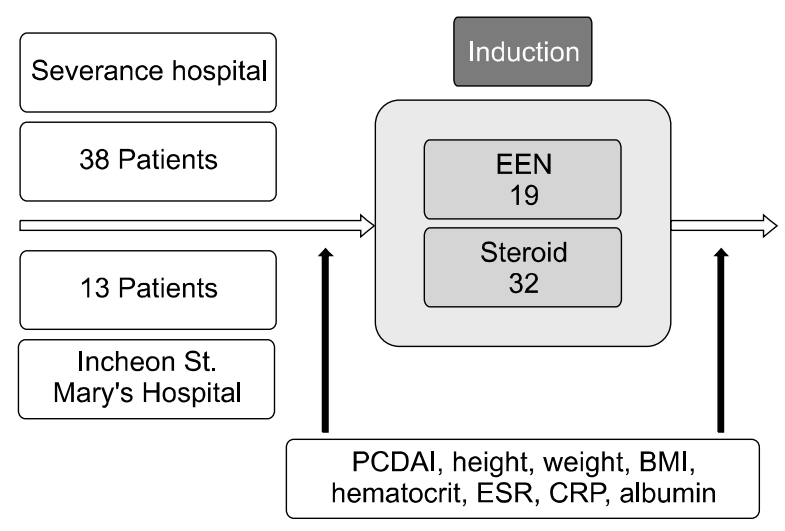

Fig. 1. Flowchart of the study.

EEN: exclusive enteral nutrition, PCDAI: Pediatric Crohn's Disease Activity Index, BMI: body mass index, ESR: erythrocyte sedimentation rate, CRP: C-reactive protein. 
BMI Z-score, Hct level, ESR, CRP level, and albumin level. Growth status (i.e., height, weight, and BMI status) was assessed by calculating the Z-score using the 2017 Korean National Growth Chart for children and adolescents (http://www.cdc.go.kr). This study was approved by the institutional review board of Severance Hospital, Yonsei University, Seoul, South Korea, and Catholic Medical Center, The Catholic University of Korea, Seoul, South Korea.

\section{Statistical analysis}

The Mann-Whitney $U$-test was used to compare continuous variables between the EEN and CS groups. Differences before and after induction between both groups were compared using the Wilcoxon signed-rank test. Categorical variables were analyzed using the chi-square test or Fisher's exact test. All statistical analyses were performed using SPSS version 23.0 (IBM Co., Armonk, NY, USA). A $p$-value $<0.05$ was considered statistically significant.

\section{RESULTS}

\section{Baseline characteristics}

Between 2005 and 2017, a total of 85 pediatric patients were diagnosed with $\mathrm{CD}$. Thirty-four patients who lacked medical records or who had not adhered to EEN or CS therapy during the induction period were excluded, leaving 51 patients for inclusion. Among these patients, 19 and 32 patients received EEN and CSs for induction therapy, respectively. Thirty-seven patients $(72.5 \%)$ were male, and the median age at baseline was 13.0 years (range, 3.0-7.0 years). Comparison of baseline characteristics between the two groups did not show significant differences except ESR, which was significantly higher in the CS group compared to the EEN group (median 77.0 vs. $58.0, p=0.021$ ) (Table 1).

Table 1. Baseline Characteristics of the Patients before Induction

\begin{tabular}{|c|c|c|c|c|c|}
\hline \multirow{2}{*}{ Characteristic } & \multirow{2}{*}{\multicolumn{2}{|c|}{ Total }} & \multicolumn{3}{|c|}{ Before induction } \\
\hline & & & EEN & Steroids & $p$-value \\
\hline Sex, male & $37 / 51$ & $(72.5)$ & $15 / 19(78.9)$ & $22 / 32(68.8)$ & 0.435 \\
\hline Age $(y)$ & 13.0 & $(3.0-17.0)$ & $14.0(9.0-17.0)$ & $13.0(3.0-17.0)$ & 0.414 \\
\hline PCDAI & 40.0 & $(12.5-60.0)$ & $30.0(12.5-60.0)$ & $42.5(15.0-60.0)$ & 0.056 \\
\hline Disease location & & & & & 0.130 \\
\hline $\mathrm{Ll}$ & 6 & $(11.8)$ & $(0.0)$ & $6(18.8)$ & \\
\hline $\mathrm{L} 2$ & 5 & $(9.8)$ & $3(15.8)$ & $2(6.3)$ & \\
\hline L3 & 38 & $(74.5)$ & $16(84.2)$ & $22(68.8)$ & \\
\hline Any L4 involvement & 5 & $(9.8)$ & $1(5.3)$ & $4(12.5)$ & \\
\hline Disease behavior & & & & & 0.251 \\
\hline B1 & 41 & $(80.4)$ & $16(84.2)$ & $25(78.1)$ & \\
\hline B2 & 9 & $(17.6)$ & $2(10.5)$ & $7(21.9)$ & \\
\hline B3 & 1 & $(1.9)$ & $1(5.3)$ & $0(0.0)$ & \\
\hline Perianal disease & 22 & $(43.1)$ & $11(57.9)$ & $11(34.4)$ & 0.101 \\
\hline Height Z score & -0.12 & $(-3.51$ to 2.55$)$ & $0.07(-2.52$ to 2.55$)$ & $-0.30(-3.51$ to 1.65$)$ & 0.136 \\
\hline Weight Z score & -1.19 & $(-3.77$ to 2.21$)$ & $-1.02(-3.77$ to 2.21$)$ & $-1.28(-3.61$ to 1.00$)$ & 0.340 \\
\hline BMI Z score & -1.43 & $(-3.35$ to 2.11$)$ & $-1.58(-3.09$ to 2.11$)$ & $-1.31(-3.35$ to 1.26$)$ & 0.984 \\
\hline Hematocrit (\%) & 36.5 & $(27.0$ to 44.1$)$ & $34.7(27.0$ to 44.1$)$ & $36.7(27.9$ to 41.8$)$ & 0.381 \\
\hline $\operatorname{ESR}(\mathrm{mm} / \mathrm{h})$ & 67.0 & (2.0 to 120.0$)$ & $58.0(17.0$ to 98.0$)$ & $77.0(2.0$ to 120.0$)$ & 0.021 \\
\hline CRP $(\mathrm{mg} / \mathrm{L})$ & 41.3 & $(0.4$ to 160.0$)$ & 43.9 (2.5 to 96.2$)$ & $36.6(0.4$ to 159.9$)$ & 0.842 \\
\hline Albumin $(\mathrm{g} / \mathrm{dL})$ & 3.3 & $(2.3$ to 4.5$)$ & $3.3(2.5$ to 4.5$)$ & $3.4(2.3$ to 4.5$)$ & 0.538 \\
\hline
\end{tabular}

Values are presented as number (\%) or median (range).

EEN: exclusive enteral nutrition, PCDAI: Pediatric Crohn's Disease Activity Index, BMI: body mass index, ESR: erythrocyte sedimentations rate, CRP: C-reactive protein.

L1 -4: terminal ileal \pm limited cecal disease (L1), colonic disease (L2), ileocolonic disease (L3), upper disease (L4).

$\mathrm{B1}$ : non-stricturing and non-penetrating, B2: stricturing, B3: penetrating. 


\section{Comparison of clinical remission rates between the EEN and CS group}

The overall clinical remission rate was $70.6 \%$ $(36 / 51)$ after induction. Fifteen of 19 patients $(78.9 \%)$ in the EEN group and 21 of 32 patients $(65.6 \%)$ in the CS group were in clinical remission after induction $(p=0.313)$. Furthermore, clinical remission rates according to disease location, luminal behavior and perianal disease did not significantly differ between the two groups (Table 2).

\section{Comparison between pre- and post-induction variables in each group}

In the EEN group, all clinical and laboratory variables except for height Z-score significantly improved after induction therapy. PCDAI scores, Hct levels, ESR, and CRP levels significantly decreased $(p<0.05)$, whereas weight Z-scores, BMI Z-scores, and albumin levels significantly increased $(p<0.05)$ after induction therapy. Additionally, similar results were noted in the CS group after induction $(p<0.05)$ (Table 3$)$.

Table 2. Comparison of Clinical Remission Rates between the Two Groups

\begin{tabular}{|c|c|c|c|c|}
\hline \multirow{2}{*}{ Variable } & \multirow{2}{*}{ Total } & \multicolumn{3}{|c|}{ After induction } \\
\hline & & EEN & Corticosteroids & $p$-value \\
\hline $\begin{array}{l}\text { Clinical remission rate } \\
\text { Disease location }\end{array}$ & $36 / 51 \quad(70.6)$ & $15 / 19(78.9)$ & $21 / 32 \quad(65.6)$ & 0.313 \\
\hline Ll & $4 / 6 \quad(66.7)$ & $0 / 0(0.0)$ & $4 / 6(66.7)$ & - \\
\hline $\mathrm{L} 2$ & $5 / 5(100)$ & $3 / 3(100)$ & $2 / 2(100)$ & - \\
\hline L3 & $25 / 38 \quad(67.6)$ & $12 / 16(75.0)$ & $13 / 22(54.5)$ & 0.307 \\
\hline $\begin{array}{l}\text { Any L4 involvement } \\
\text { Disease behavior }\end{array}$ & $4 / 5(80.0)$ & $1 / 1 \quad(100)$ & $3 / 4(75.0)$ & 1.000 \\
\hline $\mathrm{Bl}$ & $29 / 41 \quad(70.7)$ & $12 / 16(75.0)$ & $17 / 25(68.0)$ & 0.734 \\
\hline B2 & $6 / 9(66.7)$ & $2 / 2(100)$ & 4/7 (57.1) & 0.500 \\
\hline B3 & 1/1 (100) & $1 / 1 \quad(100)$ & $0 / 0 \quad(0.0)$ & - \\
\hline Perianal disease & $16 / 22(72.7)$ & $7 / 11 \quad(63.6)$ & $9 / 11 \quad(81.8)$ & 0.635 \\
\hline
\end{tabular}

Values are presented as number (\%).

EEN: exclusive enteral nutrition.

L1 -4: terminal ileal \pm limited cecal disease (L1), colonic disease (L2), ileocolonic disease (L3), upper disease (L4).

B1: non-stricturing and non-penetrating, B2: stricturing, B3: penetrating.

Clinical remission was defined as a pediatric Crohn's disease activity index score $<10$.

Table 3. Comparison between Pre- and Post-induction Variables in Each Group

\begin{tabular}{|c|c|c|c|c|c|c|c|c|}
\hline \multirow{2}{*}{ Variable } & \multicolumn{3}{|c|}{ EEN } & \multirow{2}{*}{$p$-value } & \multicolumn{3}{|c|}{ Corticosteroids } & \multirow{2}{*}{$p$-value } \\
\hline & & Before & After & & & Before & After & \\
\hline PCDAI & 30.0 & $(12.5$ to 60.0$)$ & $2.5(0$ to 37.5$)$ & $<0.001$ & 42.5 & (15 to 60 ) & $5.0(0$ to 28$)$ & $<0.001$ \\
\hline Hematocrit $(\%)$ & 34.7 & $(27.0$ to 44.1$)$ & 39.8 (35.9 to 45.5$)$ & 0.001 & 36.7 & (27.9 to 41.8$)$ & $40.0(31.7$ to 48.7$)$ & 0.001 \\
\hline $\operatorname{ESR}(\mathrm{mm} / \mathrm{h})$ & 58.0 & (17 to 98$)$ & $19.0(6$ to 47$)$ & $<0.001$ & 77.0 & $(2$ to 120$)$ & $25.0(3$ to 83$)$ & $<0.001$ \\
\hline CRP (mg/L) & 43.9 & (2.5 to 96.2$)$ & $2.2(0.2$ to 23.6$)$ & $<0.001$ & 36.6 & $(0.4$ to 160.2$)$ & $2.0(0.3$ to 113.0$)$ & $<0.001$ \\
\hline Albumin $(\mathrm{g} / \mathrm{dL})$ & 3.3 & $(2.5$ to 4.5$)$ & $4.3(3.3$ to 4.8$)$ & $<0.001$ & 3.5 & (2.3 to 4.5$)$ & $4.0(3.1$ to 4.8$)$ & $<0.001$ \\
\hline Height Z-score & 0.1 & $(-2.52$ to 2.55$)$ & $0(-2.62$ to 2.52$)$ & 0.227 & -0.3 & $(-3.51$ to 1.65$)$ & $-0.3(-3.52$ to 1.26$)$ & 0.262 \\
\hline Weight Z-score & -1.0 & $(-3.77$ to 2.21$)$ & $-0.7(-3.12$ to 1.86$)$ & 0.010 & -1.3 & $(-3.61$ to 1.00$)$ & $-0.9(-3.51$ to 1.00$)$ & 0.001 \\
\hline BMI Z-score & -1.6 & $(-3.09$ to 2.11$)$ & $-0.9(-2.09$ to 1.73$)$ & 0.008 & -1.3 & $(-3.35$ to 1.26$)$ & $-0.9(-3.82$ to 2.90$)$ & 0.001 \\
\hline
\end{tabular}

Values are presented as median (range).

EEN: exclusive enteral nutrition, PCDAI: Pediatric Crohn's Disease Activity Index, ESR: erythrocyte sedimentation rate, CRP: C-reactive protein, BMI: body mass index. 
Table 4. Comparison of Changes in Variables between the Two Groups

\begin{tabular}{|c|c|c|c|c|}
\hline \multirow{2}{*}{ Variable } & \multirow{2}{*}{ Total } & \multicolumn{3}{|c|}{ Post-induction - baseline } \\
\hline & & EEN & Corticosteroids & $p$-value \\
\hline$\triangle$ PCDAI & $-32.5(-57.5$ to 5.0$)$ & $-30.0(-52.5$ to 5.0$)$ & $-33.8(-57.5$ to -7.5$)$ & 0.446 \\
\hline$\Delta$ Height Z-score & $0(-0.40$ to 1.49$)$ & $0(-0.16$ to 0.17$)$ & $0(-0.40$ to 1.49$)$ & 0.599 \\
\hline$\Delta$ Weight Z-score & $+0.3(-0.51$ to 1.95$)$ & $+0.3(-0.51$ to 0.99$)$ & $+0.3(-0.32$ to 1.95$)$ & 0.892 \\
\hline$\triangle \mathrm{BMI}$ Z-score & $+0.3(-1.23$ to 2.18$)$ & $+0.3(-0.58$ to 1.35$)$ & $+0.3(-1.23$ to 2.18$)$ & 0.668 \\
\hline$\Delta$ Hematocrit $(\%)$ & $+2.9(-5.40$ to 14.20$)$ & $+4.6(-1.60$ to 11.80$)$ & $+2.9(-5.40$ to 14.20$)$ & 0.212 \\
\hline$\Delta \operatorname{ESR}(\mathrm{mm} / \mathrm{h})$ & $-37(-108$ to 12$)$ & $-32.0(-64$ to 2$)$ & $-37.0(-108$ to 12$)$ & 0.298 \\
\hline$\Delta \mathrm{CRP}(\mathrm{mg} / \mathrm{L})$ & $-37.2(-159.24$ to 108.08$)$ & $-43.4(-84.23$ to 2.45$)$ & $-35.2(-159.24$ to 108.08$)$ & 0.837 \\
\hline$\Delta$ Albumin $(\mathrm{g} / \mathrm{dL})$ & $+0.7(-0.30$ to 1.60$)$ & $+1.0(0.0$ to 1.60$)$ & $+0.5(-0.30$ to 1.50$)$ & 0.038 \\
\hline
\end{tabular}

Values are presented as median (range).

EEN: exclusive enteral nutrition, PCDAI: Pediatric Crohn's Disease Activity Index, BMI: body mass index, ESR: erythrocyte sedimentation rate, CRP: C-reactive protein.

\section{Comparison of changes in variables between the two groups}

Differences in clinical variables before and after the induction of remission between the two groups are shown in Table 4 . There were no significant differences between both groups in the clinical remission rate, PCDAI score, Hct level, ESR, CRP level, height Z-score, weight Z-score, and BMI Z-score before and after induction. However, albumin levels in the EEN group significantly improved after induction compared with that in the CS group $(p=0.038)$ (Table 4$)$.

\section{DISCUSSION}

This study showed that the effects of EEN with a polymeric diet did not differ from those of CSs for the induction of remission in Korean pediatric CD patients. Clinical remission rates after 8 weeks of induction therapy were not significantly different between pediatric CD patients treated with CSs and EEN ( $65.6 \%$ vs. $78.9 \%, p=0.318)$. Our results suggest that EEN with a polymeric diet is as effective as CSs for the induction of remission in Korean pediatric CD patients.

The management strategy for pediatric $\mathrm{CD}$ is evolving. Managing pediatric CD does not simply involve the induction of remission but considers growth and pubertal development, and it is neces- sary to minimize adverse effects due to drugs and disease complications [16]. Thus, it is more difficult for physicians to provide a management plan for pediatric CD patients. Although the exact mechanism of EEN is unclear, it has been widely used in pediatric $\mathrm{CD}$ patients as an induction therapy because it is associated with few complications and is effective with respect to growth and pubertal development [17].

In 2014, the European Crohn's and Colitis Organisation (ECCO) and the European Society for Paediatric Gastroenterology, Hepatology, and Nutrition (ESPGHAN) issued consensus guidelines that recommend EEN as first-line therapy for the induction of remission in children with active CD [3]. According to the ECCO/ESPGHAN guideline, the use of CSs should be avoided in children whenever possible owing to their adverse effects, while oral CSs for induction therapy can be an option when children with moderate to severe active luminal CD cannot adhere to EEN $[3,11]$. Furthermore, previous studies have shown that CSs do not improve endoscopic and histologic inflammatory lesions despite their beneficial effect on clinical response $[18,19]$.

A previous study by Grover et al. [20] showed the efficacy of EEN for inducing clinical remission $(84 \%)$, mucosal remission $(58 \%)$, and transmural remission $(21 \%)$ in pediatric CD. Furthermore, early good endoscopic response with EEN induction led to decreased relapse, hospitalization, need for anti-tu- 
mor necrosis factor therapy, and surgical resection at 1 year [20]. Several retrospective studies have suggested that EEN is not only capable of inducing clinical remission but also of improving bone metabolism, increasing muscle mass, and decreasing visceral fat $[21,22]$. Therefore, with many such advantages, EEN has become the preferred induction therapy worldwide [23].

In a randomized controlled trial in 2006, Borrelli et al. [11] showed comparable clinical remission rates for EEN with a polymeric diet (79\%) and CS therapy (67\%). The present study obtained similar results, with a clinical remission rate of $78.9 \%$ and $65.6 \%$ for EEN and CSs, respectively. Day et al. [24], in a systemic review in 2008, showed that disease location can affect the efficacy of EEN. However, Buchanan et al. [25] indicated that disease phenotype does not affect clinical remission and suggested that EEN should be offered to all pediatric CD patients. Furthermore, Day et al. [26] reported that EEN can also be beneficial to children with perianal disease, whether alone or in combination with luminal disease. The association between disease location and treatment outcomes of EEN was not observed in our study.

Although several studies have suggested EEN with a polymeric diet as a first-line treatment for $C D$, our study is the first to show its effects in Korean children $[3,11,27]$. The findings of our study suggest that the same results could be obtained with EEN using a specific polymeric product regardless of ethnicity. Furthermore, because only the effect of EEN with a monomeric diet has been confirmed in Korean adolescents, the government has funded only the monomeric diet in children with $\mathrm{CD}$ in Korea [12]. As the effectiveness of EEN with a polymeric diet has been confirmed by this study, patients are expected to choose from a variety of EEN formulas to suit their taste. Additionally, because a polymeric diet is less expensive and tastes better than a monomeric diet, this may increase the success rate of EEN with a polymeric diet [12].

The present study has some limitations. First, it was not a prospective randomized controlled trial.
Thus, there might have been a selection bias that could have affected the results. In this study, the CS group had a higher PCDAI score and ESR than the EEN group before induction. Patients with more severe disease activity may have received CSs for induction therapy, which may have resulted in the introduction of a selection bias. Second, colonoscopy findings or fecal calprotectin levels were not assessed. Mucosal healing has recently emerged as the optimal treatment target in CD management. Thus, endoscopic evaluation and treatment optimization are crucial in the current era of treat-to-target $[28,29]$. Third, only short-term follow-up results were included. Moreover, we were unable to investigate the adverse events of both treatments owing to the retrospective character of this study and the short-term follow-up period. Fourth, due to the lack of information on the small bowel in some patients, analysis results according to disease location may not be accurate. Despite these limitations, our study, to our knowledge, is the first to evaluate the effectiveness of EEN with a polymeric diet for the induction of remission in Korean children with active CD.

In conclusion, EEN with an oral polymeric diet was not inferior to CSs for the induction of remission in Korean children with CD. Induction therapy with polymeric EEN should be considered as first-line treatment along with monomeric EEN in these patients, considering the well-known adverse events associated with CS treatment.

\section{REFERENCES}

1. Van Limbergen J, Russell RK, Drummond HE, Aldhous MC, Round NK, Nimmo ER, et al. Definition of phenotypic characteristics of childhood-onset inflammatory bowel disease. Gastroenterology 2008;135:1114-22.

2. Lee EJ, Moon JS, Ko JS, Yang HR, Jang JY, Kim JW, et al. Effect of the baseline vitamin D level on growth outcome in pediatric Crohn disease. Pediatr Gastroenterol Hepatol Nutr 2017;20:41-6.

3. Ruemmele FM, Veres G, Kolho KL, Griffiths A, Levine A, Escher JC, et al. Consensus guidelines of ECCO/ ESPGHAN on the medical management of pediatric 
Crohn's disease. J Crohns Colitis 2014;8:1179-207.

4. Whitten KE, Rogers P, Ooi CY, Day AS. International survey of enteral nutrition protocols used in children with Crohn's disease. J Dig Dis 2012;13:107-12.

5. Stewart M, Day AS, Otley A. Physician attitudes and practices of enteral nutrition as primary treatment of paediatric Crohn disease in North America. J Pediatr Gastroenterol Nutr 2011;52:38-42.

6. Dziechciarz P, Horvath A, Shamir R, Szajewska H. Meta-analysis: enteral nutrition in active Crohn's disease in children. Aliment Pharmacol Ther 2007;26: 795-806.

7. Heuschkel RB, Menache CC, Megerian JT, Baird AE. Enteral nutrition and corticosteroids in the treatment of acute Crohn's disease in children. J Pediatr Gastroenterol Nutr 2000;31:8-15.

8. Zachos M, Tondeur M, Griffiths AM. Enteral nutritional therapy for induction of remission in Crohn's disease. Cochrane Database Syst Rev 2007;(1):CD000542.

9. Ludvigsson JF, Krantz M, Bodin L, Stenhammar L, Lindquist B. Elemental versus polymeric enteral nutrition in paediatric Crohn's disease: a multicentre randomized controlled trial. Acta Paediatr 2004;93:327-35.

10. Soo J, Malik BA, Turner JM, Persad R, Wine E, Siminoski K, et al. Use of exclusive enteral nutrition is just as effective as corticosteroids in newly diagnosed pediatric Crohn's disease. Dig Dis Sci 2013;58:3584-91.

11. Borrelli O, Cordischi L, Cirulli M, Paganelli M, Labalestra V, Uccini S, et al. Polymeric diet alone versus corticosteroids in the treatment of active pediatric Crohn's disease: a randomized controlled open-label trial. Clin Gastroenterol Hepatol 2006;4:744-53.

12. Kim HJ, Kim Y, Cho JM, Oh SH, Kim KM. Therapeutic efficacy of oral enteral nutrition in pediatric Crohn's disease: a single center non-comparative retrospective study. Yonsei Med J 2016;57:1185-91.

13. Satsangi J, Silverberg MS, Vermeire S, Colombel JF. The Montreal classification of inflammatory bowel disease: controversies, consensus, and implications. Gut 2006;55:749-53.

14. Hyams JS, Ferry GD, Mandel FS, Gryboski JD, Kibort PM, Kirschner BS, et al. Development and validation of a pediatric Crohn's disease activity index. J Pediatr Gastroenterol Nutr 1991;12:439-47.

15. Hyams J, Markowitz J, Otley A, Rosh J, Mack D, Bousvaros A, et al. Evaluation of the pediatric crohn disease activity index: a prospective multicenter experience. J Pediatr Gastroenterol Nutr 2005;41:416-21.

16. Pigneur B, Seksik P, Viola S, Viala J, Beaugerie L, Girardet JP, et al. Natural history of Crohn's disease: comparison between childhood- and adult-onset disease. Inflamm Bowel Dis 2010;16:953-61.

17. Levine A, Wine E. Effects of enteral nutrition on Crohn's disease: clues to the impact of diet on disease pathogenesis. Inflamm Bowel Dis 2013;19:1322-9.

18. Landi B, Anh TN, Cortot A, Soule JC, Rene E, Gendre JP, et al. Endoscopic monitoring of Crohn's disease treatment: a prospective, randomized clinical trial. The Groupe d'Etudes Therapeutiques des Affections Inflammatoires Digestives. Gastroenterology 1992;102: 1647-53.

19. Olaison G, Sjödahl R, Tagesson C. Glucocorticoid treatment in ileal Crohn's disease: relief of symptoms but not of endoscopically viewed inflammation. Gut 1990;31: 325-8.

20. Grover Z, Muir R, Lewindon P. Exclusive enteral nutrition induces early clinical, mucosal and transmural remission in paediatric Crohn's disease. J Gastroenterol 2014;49:638-45.

21. Werkstetter KJ, Schatz SB, Alberer M, FilipiakPittroff B, Koletzko S. Influence of exclusive enteral nutrition therapy on bone density and geometry in newly diagnosed pediatric Crohn's disease patients. Ann Nutr Metab 2013;63:10-6.

22. Li Y, Zhu W, Gong J, Zuo L, Zhang W, Gu L, et al. Influence of exclusive enteral nutrition therapy on visceral fat in patients with Crohn's disease. Inflamm Bowel Dis 2014;20:1568-74.

23. Lawley M, Wu JW, Navas-López VM, Huynh HQ, Carroll MW, Chen M, et al. Global variation in use of enteral nutrition for pediatric Crohn disease. J Pediatr Gastroenterol Nutr 2018;67:e22-9.

24. Day AS, Whitten KE, Sidler M, Lemberg DA. Systematic review: nutritional therapy in paediatric Crohn's disease. Aliment Pharmacol Ther 2008;27: 293-307.

25. Buchanan E, Gaunt WW, Cardigan T, Garrick V, McGrogan P, Russell RK. The use of exclusive enteral nutrition for induction of remission in children with Crohn's disease demonstrates that disease phenotype does not influence clinical remission. Aliment Pharmacol Ther 2009;30:501-7.

26. Day AS, Whitten KE, Lemberg DA, Clarkson C, Vitug-Sales M, Jackson R, et al. Exclusive enteral feeding as primary therapy for Crohn's disease in Australian children and adolescents: a feasible and effective approach. J Gastroenterol Hepatol 2006;21: 1609-14.

27. Ruuska T, Savilahti E, Mäki M, Ormälä T, Visakorpi JK. Exclusive whole protein enteral diet versus prednisolone in the treatment of acute Crohn's disease in children. J Pediatr Gastroenterol Nutr 1994;19:175-80. 
28. Bouguen G, Levesque BG, Feagan BG, Kavanaugh A, Peyrin-Biroulet L, Colombel JF, et al. Treat to target: a proposed new paradigm for the management of Crohn's disease. Clin Gastroenterol Hepatol 2015;13: 1042-50.e2.
29. Kang B, Choe YH. Early biologic treatment in pediatric Crohn's disease: catching the therapeutic window of opportunity in early disease by treat-to-target. Pediatr Gastroenterol Hepatol Nutr 2018;21:1-11. 